\title{
Myeloproliferative syndrome of monosomy 7: A brief report
}

\author{
Terezinha de Jesus Marques-Salles ${ }^{1}$, Eliane Maria Soares-Ventura ${ }^{1}$, Nathalia Lopes de Oliveira ${ }^{1}$, \\ Mariluze Silva ${ }^{1}$, Reijane Assis ${ }^{3}$, Vera Lúcia Lins de Morais ${ }^{1}$, Luize Otero ${ }^{2}$, Teresa Fernandez ${ }^{2}$, \\ Maria do Socorro Pombo-de-Oliveira ${ }^{2}$, Maria Tereza Cartaxo Muniz ${ }^{1}$ and Neide Santos ${ }^{3}$ \\ ${ }^{1}$ Centro de Oncohematologia Pediátrica, Hospital Universitário Oswaldo Cruz, \\ Universidade de Pernambuco, Recife, PE, Brazil. \\ ${ }^{2}$ Instituto Nacional do Câncer, Rio de Janeiro, RJ, Brazil. \\ ${ }^{3}$ Universidade Federal de Pernambuco, Departamento de Genética, Recife, PE, Brazil.
}

\begin{abstract}
We report the case of a five-month-old black male infant who had recurrent episodes of respiratory infections and also presented anemia and enlargements of the spleen, liver and lymphnodes. Hematological analysis revealed morphological abnormalities with megaloblastic dyserythropoiesis, while fetal hemoglobin assaying showed normal levels. Conventional and molecular cytogenetic analysis revealed monosomy of chromosome 7 . Despite all therapeutic efforts during allogenic bone marrow transplantation, the child died due to generalized infection. The clinical and genetic distinctions between monosomy 7 syndrome and myelodysplastic disorders in childhood are discussed.
\end{abstract}

Key words: leukemia, monosomy 7, myeloproliferative syndrome.

Received: July 23, 2007; Accepted: October 1, 2007.

Monosomy 7 is the most common cytogenetic abnormality among myeloid disorders during childhood. It can be found in both preleukemic myelodysplastic syndrome (MDS) and acute myelogenous leukemia (AML). In patients with AML, monosomy suggests involvement of pluripotent hematopoietic stem cells in the leukemic process. Monosomy 7 also occurs in some patients who are reported as having juvenile myelomonocytic leukemia (JMML) (Johnson and Cotter, 1997; Hasle et al., 1999).

JMML is a rare malignant disease, representing less than $5 \%$ of childhood leukemia. Because of the heterogeneity of its clinical features, JMML can be misdiagnosed as other myeloproliferative disorders. However, most JMML cases present splenomegaly, pallor, hepatomegaly, lymphadenopathy and facial eczematous rash. The hematological profile includes high white blood cell (WBC) counts $\left(<100,000 / \mathrm{mm}^{3}\right)$, monocytes, anemia with variable normoblastemia, thrombocytopenia and autoantibodies. Fetal hemoglobin $(\mathrm{HbF})$ and immunoglobulin levels are usually elevated, whereas leukocyte alkaline phosphatase levels are lowered and the Philadelphia chromosome is always absent (Niemeyer et al., 1997; Hasle et al., 1999, 2003; Lopes et al., 2006; Hasle, 2007).

Send correspondence to Terezinha de Jesus Marques-Salles. Laboratório de Citogenética Humana, Centro de Oncohematologia Pediátrica, Hospital Oswaldo Cruz, Rua Arnóbio Marques 310, 50100-130 Recife, PE, Brazil. E-mail: tjmsalles@uol.com.br.
A 5-month-old black male infant was hospitalized in CEONHPE, city of Recife, in June 2002, with intense pallor, fever and persistent diarrhea. At physical examination, he presented abnormal abdominal features due to a huge hepatosplenomegaly (which had first been noticed two months earlier). No congenital stigmata signs were found. He was treated with antibiotics, antifungals and blood transfusions. He was investigated for acute leukemia (AL), thalassemia syndromes, congenital dyserythropoietic anemia (CDA) and myelodysplastic syndrome (MDS). The hematological findings were: hemoglobin $3.9 \mathrm{~g}$; hematocrit $17 \%$; median corpuscular volume and reticulocyte count $60 \%$; WBC $24,000 / \mathrm{mm}^{3}$; elevated circulating monocytes $\left(5,320 / \mathrm{mm}^{3}\right)$; and platelet count $23,000 / \mathrm{mm}^{3}$. Biochemical tests showed very high levels of LDH (more than $20,000 / \mathrm{mm}^{3}$ ) and the uric acid concentration was $13 \mathrm{mg} / \mathrm{dL}$. Bone marrow (BM) aspirates were morphologically characterized by erythroid hyperplasia with dyserythropoiesis. The erythroid cells were either binucleated or multinucleated with asynchronous nucleus-cytoplasm ratio. The neutrophil compartment showed moderated hyperplasia and $6 \%$ blast cells. Hemoglobin assaying showed $\mathrm{HbA} 95 \%, \mathrm{HbA}_{2} 2.5 \%$ and $\mathrm{HbF} 2 \%$; positive serology for herpes virus; negative findings for HIV, HTLV-1/2 and CMV (IgG and IgM); unreactive quantitative and qualitative VDRL and antinuclear antibodies (FAN); and anti-I positive cold antibodies. Cytogenetic analysis was per- 
formed on BM aspirates, following the standard G-banding procedure, and chromosomes were identified and arranged in accordance with ISCN (2005). Karyotyping revealed 45,XY,-7[15]/46,XY [5]. Fluorescence in situ hybridization (FISH), performed with spectrum orange whole chromosome painting [WCP7 - Vysis], confirmed monosomy 7. Molecular analysis to investigate $N$-ras mutations produced normal results.

The child evolved with serious recurrent episodes of respiratory infections due to bacterial and fungal organisms, despite antibiotic therapy. The refractory disease was characterized by episodes of opportunistic infectious, spleen enlargement and persistent anemia, thrombocytopenia and circulating erythroblast cells. He was treated with cytarabin, $\alpha$-interferon and blood transfusions. Because of severe weight loss, daily fever and worsening of the infectious process, a new treatment with 6-mercaptopurine and ara-C in low doses was started. He presented partial clinical improvement and reduction of the splenomegaly, but the infectious episodes persisted. He underwent a splenectomy procedure, and allogeneic bone marrow transplantation was performed. Despite all the therapeutic efforts, he died of generalized infection.

There are few reports in the literature on childhood MDS. Thus, in order to standardize the diversity of classification and establish the incidence of MDS in children, a group of specialists have gathered together the clinical, laboratory, cytogenetic and molecular biological characteristics of this rare disease and have proposed criteria for diagnosing and treating childhood MDS (Lopes et al., 2006; Hasle, 2007).

The first systematic attempt at morphological classification of MDS was provided by the French-AmericanBritish group (Bennett et al., 1982). Soon afterwards, controversies regarding MDS arose from reports on patients with JMML. This pathological entity, like myeloproliferative syndrome, resembles MDS in several overlapping features. To try to solve this problem the World Health Organization (WHO) proposed that cases with WBC count less than $13,000 / \mathrm{mm}^{3}$ should be classified as MDS, whereas those with WBC more than $13,000 / \mathrm{mm}^{3}$ should be classified as a hybrid group of so-called MDS/myeloproliferative disease, in which JMML is included. This current approach includes all the cases previously classified as JCML, chronic myelomonocytic leukemia (LMMC) and monosomy 7 syndrome (Hasle et al., 1999; Luna-Fineman et al., 1999; Nosslinger et al., 2001; Hasle, 2007).

Therefore, the patient analyzed in the present report had a diagnosis of JMML, because he presented intense pallor, huge splenomegaly and recurrent infections at the age of five months. The laboratory analyses consisted of cytogenetic and molecular analysis and showed monosomy 7 without additional $N$-Ras mutations. It is worth mentioning the importance of the viral serology tests performed in this case, because some infectious diseases can also mimic
JMML; for example, neonatal cytomegalovirus and human herpes virus (HHV) (Lorenzana et al., 1997; Pinkel, 1998).

It is well recognized that there is a close association between neurofibromatosis type 1 (NF1), monosomy 7 and JMML. The proposed pathway mechanism for this association is based on the activation of the Ras gene by point mutation, which is found in approximately $40 \%$ of the patients with MDS (Miyauchi et al., 1994). Loss of the normal NF1 allele is a common finding in children with NF1 who have JMML and monosomy 7 (Bollag et al., 1996). Furthermore, the somatic PTPN11 mutation is also observed in $35 \%$ of the children with JMML, thus making molecular genetics very helpful in diagnosing JMML with mutually exclusive abnormalities or an association with clinical features (Lauchle et al., 2006).

JMML has been described as an aggressive illness, with overall survival of approximately nine months. Patients often present repeated bacterial infectious episodes, and most untreated patient die from organ failure due to infiltration of leukemic cells or infectious processes (Niemeyer et al., 1997). Blast crises and/or transformation seldom occur.

So far, no therapeutically specific and consensual approach to treatment has been found. Single agent or combination therapies using mercaptopurine, ara- $\mathrm{C}, 6$-thioguanine, interferon-alpha and vepesid have been applied, but the clinical benefits remain controversial. Currently, allogenic hematopoietic stem cell transplantation (HSCT) represents best choice for curative treatment, for younger patients with a compatible donor (Lilleyman et al., 1977; Locatelli et al., 2005; Bergstraesser et al., 2007). However, about $50 \%$ of the patients become ill again at a mean age of four months, which gives rise to the need for complementary treatment to prevent the return of the disease (Locatelli et al., 2005). Retinoic acid (isotretinoin) has been shown to have in-vitro and in-vivo activity in JMML and the drug is included both before and after HSCT, but still with uncertain results. More recently, novel agents directed towards molecular targets have been evaluated. Farnesyltransferase inhibitors were tested in a phase II window study as part of the Children's Oncology Group study on patients with JMML, and showed complete or partial response in $58 \%$ of the cases, thereby demonstrating the opening of new therapeutic possibilities for this specific disease (Castleberry et al., 2005).

Cooperative groups gathering significant numbers of children with MDS will be important for enabling evaluation of the clinical response to current treatments, thereby providing new therapeutic strategies for this rare malignancy.

\section{Acknowledgment}

This work was partially supported by grants from Fundação de Amparo à Ciência e Tecnologia do Estado de Pernambuco (FACEPE). The authors are grateful to Pro- 
grama Criança e Vida for the helpful support within the childhood cancer care network.

\section{References}

Bennett JM, Catovsky D, Daniel MT, Flandrin G, Galton DA, Gralnick HR and Sultan C (1982) Proposals for the classification of the myelodysplastic syndromes. Br J Haematol 51:189-99.

Bergstraesser E, Hasle H, Rogge T, Fischer A, Zimmermann M, Noellke P and Niemeyer CM (2007) Non-hematopoietic stem cell transplantation treatment of juvenile myelomonocytic leukemia: A retrospective analysis and definition of response criteria. Pediatr Blood Cancer 49:629-633.

Bollag G, Clapp DW, Shih S, Adler F, Zhang YY, Thompson P, Lange BJ, Freedman MH, McCornick F, Jacks T et al. (1996) Loss of NF1 results in activation of the Ras signaling pathway and leads to aberrant growth in haematopoietic cells. Nat Genet 12:144.

Castleberry RP, Loh ML, Jayaprakash N, Peterson A, Casey V, Chang M, Widemann B and Emanuel PD (2005) Phase II window study of the farnesyltransferase inhibitor R115777 (Zarmestra) in untreated juvenile myelomonocytic leukemia (JMML): A children's oncology group study. Blood 106:Abstract 2587.

Hasle H (2007) Myelodysplastic and myeloproliferative disorders in children. Curr Opin in Pediat 19:1-8.

Hasle H, Aricò M, Basso G, Biondi A, Cantù Rajnoldi A, Creutzig U, Fenu S, Fonatsch C, Haas OA, Harbott J et al. (1999) Myelodysplastic syndrome, juvenile myelomonocytic leukemia, and acute myeloid leukemia associated with complete or partial monosomy 7. Leukemia 13:376-385.

Hasle H, Niemeyer CM, Chessells JM, Baumann I, Bennett JM, Kerndrup G and Head DR (2003) A pediatric approach to the WHO classification of myelodysplastic and myeloproliferative diseases. Leukemia 17:277-282.

ISCN (2005) An International System for Human Cytogenetic Nomenclature (Cytogenetic \& Genome Research). Shaffer LG and Tommerup N (ed). Karger, Basel, 130 pp.
Johnson E and Cotter FE (1997) Monosomy 7 and 7q- associated with myeloid malignancy. Blood Rev 11:46-55.

Lauchle JO, Braun BS, Loh ML and Shannon K (2006) Inherited predispositions and hyperactive Ras in myeloid leukemogenesis. Pediatr Blood Cancer 46:579-585.

Lilleyman JS, Harrison JF and Black JA (1977) Treatment of juvenile chronic myeloid leukemia with sequential subcutaneous cytarabine and oral mercaptopurine. Blood 49:559-562.

Locatelli F, Nollke P, Zecca M, Korthof E, Lanino E, Peters C, Pession A, Kabisch H, Uderzo C, Bonfim CS et al. (2005) Hematopoietic stem cell transplantation (HSCT) in children with juvenile myelomonocytic leukemia (JMML): Results of the EWOG-MDS/EBMT trial. Blood 105:410-419.

Lopes LF, Lorand-Metze I, Mendes WL, Seber A and Melo LN (2006) Myelodysplastic syndromes in childhood. Rev Bras Hematol Hemoter 28:226-237.

Lorenzana A, Lyons H, Sawaf H, Higgins M, Carrigan D and Emmanuel P (1997) Human herpes virus-6 (HHV-6) infection in an infant mimicking juvenile chronic myelogenous leukemia (JCML). J Pediatr Hematol Oncol 19:370.

Luna-Fineman S, Shannon KM, Atwater SK, Masterson M, Ortega J, Sanders J, Steinherz P, Weinberg V and Lange BJ (1999) Myelodysplastic and myeloproliferative disorders of childhood: A study of 167 patients. Blood 93:459-466.

Miyauchi J, Asada M, Sasaki M, Tsunematsu Y, Kojima S and Mizutani S (1994) Mutations of the N-ras gene in juvenile chronic myelogenous leukemia. Blood 83:2248-2254.

Niemeyer CM, Arico M, Basso G, Biondi A, Cantú Rajnoldi A, Creutzig U, Haas O, Harbott J, Hasle H, Kerndrup G et al. (1997) Chronic myelomonocytic leukemia in childhood: A retrospective analysis of 110 cases. Blood 89:3534-3543.

Nosslinger T, Reisner R, Koller E, Gruner H, Tuchler H, Nowotny H, Pittermann E and Pfeilstocker M (2001) Myelodysplastic syndromes, from French-American-British to World Health Organization: Comparison of classifications on 431 unselected patients from a single institution. Blood 98:29352941.

Pinkel D (1998) Differentiating juvenile myelomonocytic leukemia from infections disease. Blood 91:365-367. Associate Editor: Emmanuel Dias Neto 